NBER WORKING PAPER SERIES

\title{
THE RESERVATION WAGE OF UNEMPLOYED PERSONS IN THE FEDERAL REPUBLIC OF GERMANY: THEORY AND EMPIRICAL TESTS
}

Wolfgang Franz

Working Paper No. 578

NATIONAL BUREAU OF ECONOMIC RESEARCH 1050 Massachusetts Avenue

Cambridge MA 02138

November 1980

This work has been supported by a grant from the "Deutsche Forschungsgemeinschaft" which is gratefully acknowledged. I am indebted to Zvi Griliches, Alan Blinder, Dan Hamermesh, Yoram Ben-Porath, Wayne Gray (NBER), Jacob Mincer (New York), R.A.L. Carter (London/Ontario), Hans Joachem Schalk (Münster), Franz Egle (Nürenberg), Gebhard Flaig, Theo Kempf, Hans Werner Sinn (Mannheim) for helpful comments. None of them are responsible for any remaining error. Any opinions expressed are those of the author and not those of the National Bureau of Economic Research. The research reported here is part of the NBER's research program in Labor Economics. 
The Reservation Wage of Unemployed Persons in the Federal Republic of Germany: Theory and Empirical Tests

\section{ABSTRACT}

This study examines the determinants of the reservation wage of unemployed persons in the Federal Republic of Germany in 1976. The theoretical section presents the derivation of an optimal reservation wage and shows the source of an ambiguity of some explanatory variables. The data basis are unemployed persons leaving the unemployment register within a given sample week. For a subset of them, we know their reservation wage and a set of personal characteristics. Other variables, such as the wage offer distribution and demand side variables, are obtained by employing other data. Methodological probiems, such as as a sample selection bias, are taken into account. As a result, individual characteristics and the wage offer distribution are dominant causes of the reservation wage, but demand side variables and the entitlement to unemployment compensation play minor roles.

Wolfgang Franz

Deparmtent of Economics University of Mannheim 6800 Mannheim 1 


\section{Zusammenfassung}

Der Beitrag untersucht Bestimmungsgrüde des sog. "Anspruchslohns" Arbeitsloser in der Bundesrepublik Deutschland im Jahre 1976. Trotz einer Vielzahl ausgefeilter Arbeitsplatzsuchmodelle muß sich die Studie auf einige hauptsächliche uberlegungen beschränken. weil die durch die Theorie vorgegebenen Variablen datenmäßig noch nicht zur Verfügung stehen. Da nicht alle Arbeitslose die entsprechenden Einkommensangaben gemacht haben, muß geprüft werden, ob und inwieweit die Schätzergebnisse aufgrund dieșer fehlenden Information verzerrt sind. Eine diesbezügliche Korrektur wurde vorgenommen. Als Ergebnis zeigt sich eine Dominanz der individuellen Merkmale und der Verteilungsfunktion der Lohnangebote für den Erklärungswert des Anspruchslohns, wohingegen unterschiedliche konjunkturelle Einflusse oder die Anspruchsberechtigung auf Arbeitslosengeld nur eine untergeordnete Rolle spielen. 
The place of economic theory is to be the servant of applied economics.

John R. Hicks (1938)

\section{INTRODUCTION}

This paper deals with the reservation wage of unemployed persons to the amount of which the duration of unemployment has often been attributed. An unemployed person searching for a job classifies all job offers in two exclusive classes: acceptable and unacceptable. The wage which separates these two classes is called the reservation wage. Hence, a job offer lower than the reservation wage is not accepted and vice versa.

This study is an attempt to narrow the gap between theoretical and empirical work on job search behaviour partly by examining the determinants of the reservation wage specified by job search models. The basis of the empirical reserach is unemployed persons leaving the unemployment register within a given sample week. For a subset of these unemployed persons we know the wage they want to receive, and a set of personal characteristics. Other variables such as the wage offer distribution and demand side variables are obtained by employing other data. Some serious methodological problems must be taken into account such as the problem of non-randomly missing data, for example.

The paper is organized as follows. Section I presents a very brief outline of a theory concerning the determinants of the reservation wage. Since this section does not intend to present a survey on job search models, no claim is made that the conclusions reported there are an exhaustive picture. A short description of the data and discussion of methodological problems is contained in Section II. Empirical results and their interpretation are reported in Section III, and a conclusion including some policy implications is given finally. 
One general caveat seems necessary which will not be repeated again. A review of the literature on job search models sometimes gives the impression that reluctant unemployed persons with too high reservation wages have replaced the unemployed breadwinner of the family as the focus of concern about joblessness. We therefore want to emphasize that search unemployment is only one part, and perhaps a minor part, of unemployment. To see this, note that job search theories usually assume that there is at least one job offer in a given time period. But there may be a considerable amount of unemployed persons who do not receive a job offer at all within a reasonable time period due to bad demand conditions, for example. Since many wages are negotiated and fixed, therefore, and employers for good economic reasons refuse to hire overqualified workers, a substantial reduction in the reservation wage and/or a search for a less qualified occupation may not help for those unemployed. To call them voluntary unemployed seems more to explain the problem away rather than to explain the facts.

\section{THEORY}

In their simplest version, job search models $1 /$ postulate that an individual maximizes expected wealth if he or she accepts a wage offer (combined with a job offer) which is not lower than his reservation wage. Let ${ }^{R}$ denote the reservation wage and $f(w)$ the known distribution of wage offers. The probability of receiving a job offer $q$ depends on personal characteristics and demand side variables denoted by $z$ and on the wage rate. $w$ is a determinant of $q$ for several reasons. First, holding capital costs constant the higher the wage rate the more likely the firm will switch to capital goods instead of using labor and, hence, the smaller the probability to receive a job offer at all. Second, $\underline{2}$ the wage rate offered may be more associated with the job than with the applicant. The higher the wage rate the longer the queue of applicants for 
this job who will be offered the job due to higher abilities and who will accept it. This again implies a decreasing chance for a given searcher to get a job offer, i.e., $\delta q / \delta w<0$. Thus the probability of receiving and accepting a job of fer $p$ in any period is given by

$$
\text { (I.1) } \quad p\left(z, w^{R}\right)=\int_{w^{R}}^{\infty} q(z, w) f(w) d w
$$

Although the individual's abilities are assumed to be invariant during the search process, there is a distribution of wage offers since prospective employers do not value them equally. The individual contacts several employers submitting different job offers. The distribution of job offers is the source of uncertainty: although its parameters are known to the searcher, each offer is a realization of a random variable.

The present value of earnings from an expected accepted job of fer is:

$$
\text { (I.2) } \quad \frac{1}{r} E\left(w \mid w \geq w^{R}\right)=\frac{1}{r} \int_{w^{R}}^{\infty} w \cdot q(z, w) f(w) d w \mid p\left(z, w^{R}\right),
$$

where the right hand side is the conditional mean of $w$ given that $w \geq w$. An infinite time horizon is assumed, hence $r$ is the constant discount rate. In the $f$ inite horizon case $1 / r_{t}$ is the present value at time 0 of one unit nominal income received in period $t$ :

(I.3) $\quad r_{t}=\frac{1}{(1+i)^{T}}\left\{\left[(1+i)^{T-t+i}-1\right] / i\right\}$,

where $\mathrm{T}$ is the finite time horizon and $i$ is the discount rate. $\underline{3}$ /

The reservation wage is optimal if the present value of accepting the reservation wage equals the present value of the gain from continuing search. The present value of the reservation wage $w^{R}$ is: ${ }^{4 /}$

$$
\text { (I.4) } \sum_{t=0}^{\infty} \frac{w^{R}}{(1+r)^{t}}=\frac{w^{R}(1+r)}{r} \text {. }
$$


The expected net worth from continuing search until receiving a wage offer equal to or better than $w^{R}$ consists of the unemployment compensation $u$ and of the expected future wage (conditional on $w^{R}$ ) provided that a job offer with a wage equal to or better than $w^{R}$ is received and accepted.

$$
\begin{aligned}
\text { (I.5) } & u+\sum_{t=1}^{\infty} \frac{p\left(z, w^{R}\right) E\left(w \mid w \geq w^{R}\right)}{(1+r)^{t}} \quad \text { (first period) } \\
& +\left[1-p\left(z, w^{R}\right)\right]\left\{\frac{u}{1+r}+\sum_{t=2}^{\infty} \frac{p\left(z, w^{R}\right) E\left(w \mid w \geq w^{R}\right)}{(1+r)^{t}}\right\} \quad \text { (second period) } \\
& +\left[1-p\left(z, w^{R}\right)\right]^{2,}\left\{\frac{u}{(1+r)^{2}}+\sum_{t=3}^{\infty} \frac{p\left(z, w^{R}\right) E\left(w \mid w \geq w^{R}\right)}{(1+r)^{t}}\right\} \quad \text { (third period) }
\end{aligned}
$$

The terms containing $u$ can be rearranged to (where $p=p\left(z, w^{R}\right)$ ):

$$
\begin{aligned}
& \text { (I.5a) } \quad u\left[1+(1-p) \frac{1}{1+r}+(1-p)^{2} \frac{1}{(1+r)^{2}}+\ldots . .\right] \\
& =u\left[\frac{1}{1-\frac{1-p}{1+r}}\right]=\frac{u(1+r)}{r+p},
\end{aligned}
$$

and after some manipulation we can write the terms containing $E\left(w \mid w \geq w^{R}\right)$ as:

$$
\begin{aligned}
& \text { (I. 5b) } \quad p \cdot E\left(w \mid w \geq w^{R}\right)\left[\sum_{t=1}^{\infty} \frac{1}{(1+r)^{t}}+(1-p) \sum_{t=2}^{\infty} \frac{1}{(1+r)^{t}}+\ldots .\right] \\
&=p \cdot E\left(w \mid w \geq w^{R}\right)\left[\frac{1}{r}+(1-p) \frac{1}{(1+r) \cdot r}+\cdots \cdot\right] \\
&=p E\left(w \mid w \geq w^{R}\right)\left[\sum_{t=0}^{\infty} \frac{(1-p)^{t}}{r(1+r)^{t}}\right] \\
&=p E(w \mid w \geq w \\
&
\end{aligned}
$$


Hence the net worth $(I .5)$ can be written as:

$$
\frac{u(1+r)}{r+p\left(z, w^{R}\right)}+p\left(z, w^{R}\right) E\left(w \mid w \geq w^{R}\right) \frac{1+r}{r\left(r+p\left(z, w^{R}\right)\right)} .
$$

The optimal reservation wage must satisfy the relationship:

$$
\frac{w^{R}(1+r)}{r}=\frac{u(1+r)}{r+p\left(z, w^{R}\right)}+\frac{p\left(z, w^{R}\right) E\left(w \mid w \geq w^{R}\right)(1+r)}{r\left[r+p\left(z, w^{R}\right)\right]},
$$

or

$$
\text { (I.7a) } \quad w^{R}=\frac{r \cdot u+p\left(z, w^{R}\right) E\left(w \mid w \geq w^{R}\right)}{r+p\left(z, w^{R}\right)} \text {. }
$$

Equation (I.7a) already reveals some interesting properties of the reservation wage. An increasing unemployment compensation implies a higher reservation wage since the costs of search become lower. Increasing the mean of the probability distribution of wage offers has the same effect. On the other hand, a lower probability of receiving and accepting a job offer, due to poor personal characteristics or bad demand conditions, tends to reduce the reservation wage. Finally, the search process can be viewed as an investment decision negatively related to the rate of discount.

If search costs $c$ (c=constant) are introduced, $\underline{5}$ the expression (I.7a) changes to:

$$
w^{R}=\frac{r \cdot u+p\left(z, w^{R}\right) \cdot E\left(w \mid w \geq w^{R}\right)-r \cdot c}{r+p\left(z, w^{R}\right)},
$$

or

$$
\text { (I. 8a) } \quad w^{R}-u=\frac{1}{r} p\left(z, w^{R}\right)\left[E\left(w \mid w \geq w^{R}\right)-w^{R}\right]-c \text {, }
$$

which corresponds with the result stated in recent studies on job search. Inserting the integral of equation (I.4) into equation (I.8a) and determining the parameters and the form of the wage distribution gives a solution for 
$w^{R}$ (if it exists) :

(I.9) $\quad w^{R}=g[f(w), r, c, u, z]$.

An infinite time horizon, a known distribution of wages, and constant costs of sampling imply a constant reservation wage over time ceteris paribus. This may, however, be an oversimplification. Several hypotheses have been offered to justify a changing reservation wage over time.

(i) If a finite time horizon (the retirement age, for example) ${ }^{7}$ is introduced, a longer search duration may still lead to a higher job offer, but as a contrary effect the remaining time in the labor force becomes shorter. Hence, due to wealth considerations the reservation wage may decline with duration.

(ii) If the individual is not or no longer entitled to unemployment compensation, he or she may reduce the reservation wage in order to become employed and thus be entitled to unemployment compensation later (again). $9 /$ or, to put it differently, in an unemployment insurance system with a finite duration of unemployment compensation payment an increase in these benefits leads to a reduction in the proportion of long-term unemployed (or other non or no longer entitled unemployed such as youths, for example) and to an increase in the proportion of short-term unemployment. The result that the reservation wage increases (decreases) for increasing unemployment payments only for those unemployed who are entitled (not entitled) to it rests, however, on a positive probability that unemployed workers will be laid off later. As has been shown by K. Burdett (1979), in the case of a zero probability of lay of the reservation wage remains unaffected by 
a change in the unemployment insurance system for those not or no longer entitled to it since the expected pay off to accepting a job will not change. In the German system, an example for this type of job is employment in the public sector.

(iii) If the distribution of job offers in unknown, the reservation wage may be a function of the searcher's beliefs. It changes according to the revisions the individual makes in the light of his experience. $\frac{10 /}{}$ In the case of an overestimated mean of the wage distribution, there may be a decreasing reservation wage and vice versa.

(iv) As has been mentioned in (iii), a further complication is the possibility of being laid off. The job search theory's explanation may be called in question if the tenure of jobs is rather short. Given that possible brevity of tenure in some jobs, an unemployed may raise his total return from search by accepting less attractive jobs from the beginning. 11 /

(v) Finally, another reason why optimal reservation wages may decline over time has been explored by introducing risk aversion into the model. Assume that the individual maximizes the expected utility of lifetime consumption (instead of the present value of income net of search costs, as assumed in most job search models). $\underline{12 /}$ The utility function may indicate decreasing absolute risk aversion. $13 /$ Since wealth decreases during the search process due to search costs and because the expected working life shortens, it follows that risk aversion increases and hence the reservation wage declines. $14 /$ Risk aversion can be influenced not only by wealth considerations, but also by personal characteristics such 
as age or marital status, for example. A married searcher who is the breadwinner for his family may be more risk averse than a single one.

Especially, the assumption of a known wage distribution is one of the most heroic theoretical assumptions of job search models and the most crucial step in the empirical test of these hypotheses. Even if we assume that a known wage distribution is sufficiently characterized by its first and second moment, problems arise due to an ambiguity of some effects. Although a higher mean for the wage distribution increases the reservation wage and hence the search duration, $\underline{15 /}$ this is not necessarily true with respect to an increase of the variance of the wage distribution. As Figure 1 shows, a higher variability in the wage offer distribution increases the probability of receiving a job offer which is greater than the reservation wage only if $w^{R}=w_{2}^{R}$, or, to put it differently, if the reservation wage is higher than the mean of the wage distribution. $\frac{16 /}{}$ In the case that the reservation wage coincides with the mean of the wage distribution, the reservation wage remains unaffected if the variance of the wage distributions changes. Hence, only a comparison of the means of both wage distributions with the reservation wage can determine the effect of a higher variance of the wage distribution theoretically to be expected.

The data which will be examined more carefully in the next section prohibit us from considering more than just the mean $\bar{w}$ and the standard deviation $\sigma_{\mathrm{w}}$ of wages in the profession to which the individual belongs. Hence, equation (I.9) changes to:

$$
\text { (I. 10) } \quad w^{R}=g\left(\bar{w}, \sigma_{w}, z, u\right) \text {, }
$$


$-9-$

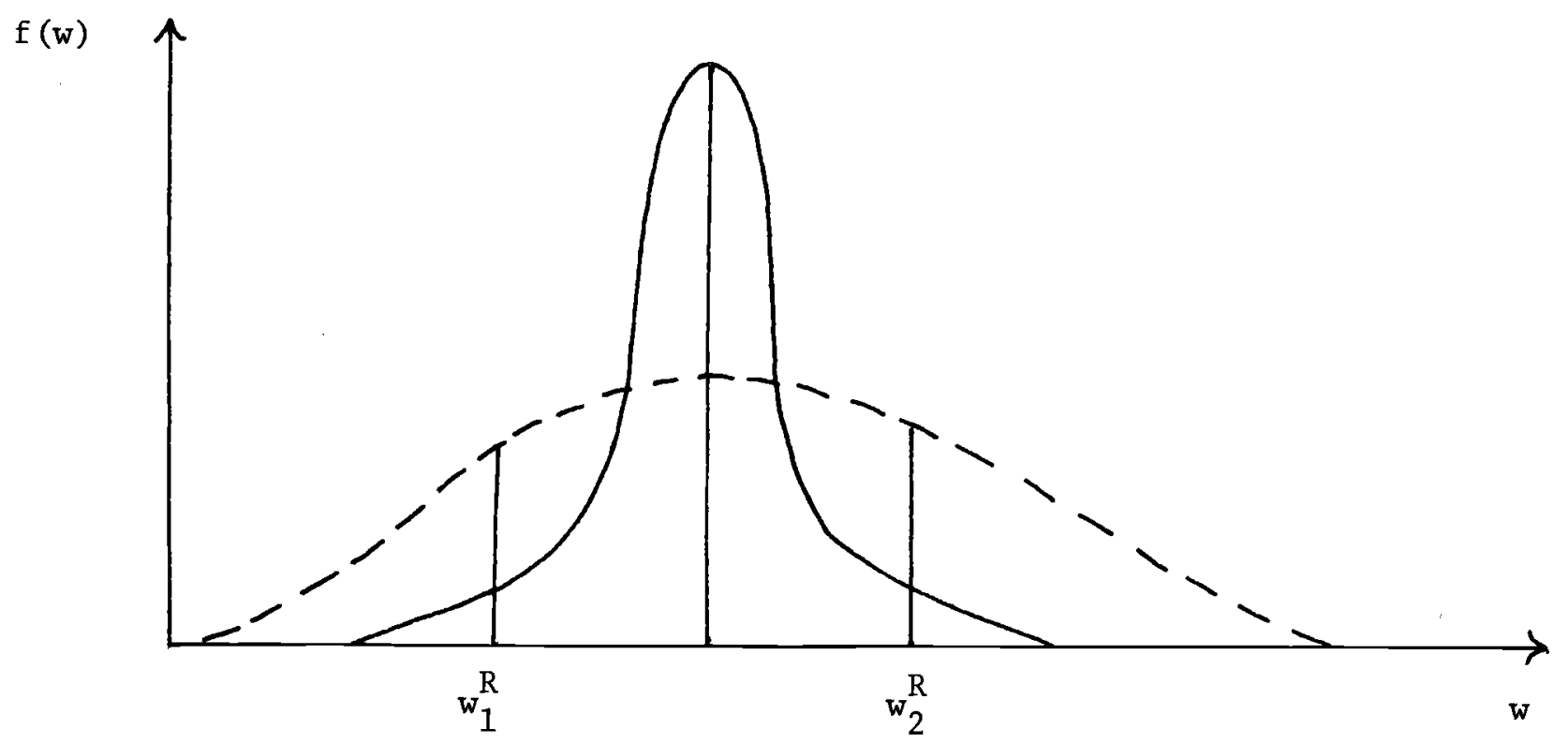

FIGURE 1: Effects of a Higher Variability of the Wage Offer Distribution 
with $\mathrm{z}$ again denoting personal characteristics and demand side variables and u denoting whether or not the individual is entitled to unemployment compensation. There is no information contained in the data about the amount of the unemployment compensation. The variables $c$ and $\mathbf{r}$ have been dropped due to a lack of data. Since variables and their definitions are dictated by the data set, we are fully aware of the fact that we cannot present a neat and illuminating test of all implications of job search theory concerning the reservation wage.

\section{DATA AND ECONOMETRIC PROBLEMS}

Before discussing the advantages and disadvantages of the data, a short description may be in order.

The sample contains all unemployed persons who left the unemployment register in approximately the last week of September 1976. Since the unemployment register includes only unemployed registered at the labor office, the sample may not be representative for all unemployed. The personal characteristics are reported for the most recent spell of unemployment and include among others age, sex, profession, marital status, citizenship, health condition, school education, vocational training, work experience, type of job contract termination (quitting, laid off, etc.), number and result of job offers given by the labor office, number and duration of all unemployment spells since 1973. No explicit information is available on whether the individual is entitled to unemployment compensation. We can, however, construct a proxy using the information about the individual's previous work history. As has been noted, the sample includes only unemployed leaving the unemployment register. Hence, we are able to circumvent a major problem associated with data on persons being unemployed at a given survey data. Such data are subject to a lengthbias since the probability to be in the survey is greater the longer the duration of unemployment. $\frac{17 /}{}$ Moreover, standard results of the theory of stochastic 
processes show that if we can assume that the unemployment spells are running long enough, the structure of our sample is equivalent to the structure of a11 unemployed persons starting their unemployment spell within a given time period. Due to this advantage our data may outperform a data set on all unemployed persons even if the latter would have been available to us.

Nevertheless, the data used herein suffer from deficiencies. A major disadvantage is that all information concerning the reservation wage is given at the very beginning of the unemployment spell. Revisions, if any, are not reported. Hence, we are not able to test whether the reservation wage is influenced by the duration of the current spell of unemployment. However, the dependence on the duration and number of previous spells may be analyzed. After eliminating some obviously incorrectly coded cases, about 6600 unemployed persons are contained in the sample. However, for only about 1100 persons is information about the desired income available. Some cases also report different dimensions about income (hourly, weekly, monthly, yearly wage rate). Since we do not know both the exact desired work time, we included only those cases where monthly wage rates are available. After correcting for some dubious cases, we finally obtain a sample size of 952 persons. $\underline{18 /}$

Since not all unemployed report their desired wage rate the question must be raised as to whether the missing answers are random or non-randomly missing data. For example, people with high desired income (compared with their previous income) may be less willing to answer this question since they fear that the labor office may not consider them to be at its disposal and refuse to pay unemployment compensation. It might be better to refuse to answer than to give a wrong answer (that means a lower wage rate than desired), since if the labor office offers a job combined with this incorrect wage rate a rejection may also lead to a disentitlement to unemployment compensation payments. 
The effect of non-randomly missing data on the estimated parameters can be evaluated. $19 /$ Let $D$ be a dummy variable which equals one if the unemployed person gives the information about the desired income and which is zero otherwise, and let $\mathrm{Z}$ be a vector of explanatory variables of this choice to answer or not to answer. An answer is given when $\mathrm{Z}$ and a random component $u_{1}$ together exceed some threshold value. $\frac{20 /}{}$

$$
\begin{aligned}
& \text { (II.1) } \mathrm{D}=1 \text { if } \mathrm{Z} \alpha+\mathrm{u}_{1} \geq 0 \\
& \mathrm{D}=0 \text { if } \mathrm{Z} \alpha+\mathrm{u}_{1}<0 .
\end{aligned}
$$

Further, let $\mathrm{V}$ be a vector of the explanatory variables of the reservation wage:

$$
\text { (II. 2) } \quad w^{R}=v_{B}+u_{2}
$$

For notational convenience we drop the subscript $i$ referring to the $i-t h$ individual. We only observe $w^{R}$ if $D=1$. Hence:

$$
\text { (II.3) } \quad E\left(w^{R} \mid v, z \text {, and } D=1\right)=v_{B}+E\left(u_{2} \mid v, Z \text {, and } D=1\right) \text {. }
$$

Integrating out $\mathrm{V}$ yields $: \underline{21 /}$

$$
\text { (II.4) } \quad E\left(w^{R} \mid V, Z \text {, and } D=1\right)=V_{\beta}+\rho_{12} \sigma_{2} / \sigma_{1} E\left(u_{2} \mid Z \text {, and } D=1\right)
$$

where a bivariate normal distribution for $u_{1}$ and $u_{2}$ is assumed with mean zero, variances $\sigma_{1}^{2}$ and $\sigma_{2}^{2}$, and correlation $\rho_{12}$.

As can be seen, as long as there is a correlation between the residuals of the choice to answer - function and the reservation wage equation the least squares coefficients of the subsample are not consistent estimators of $\beta$ because:

(II.5) $\quad E\left(w^{R} \mid V, Z\right.$, and $\left.D=I\right) \neq V_{B}$. 
As has been shown by J.J. Heckman (1976), this expression can be transformed to:

$$
\mathrm{E}\left(\mathrm{w}^{\mathrm{R}} \mid \mathrm{V}, \mathrm{Z} \alpha / \sigma_{1}, \mathrm{D}=1\right)=\mathrm{V} \beta+\rho_{12} \sigma_{2} \mathrm{M}\left(\mathrm{Z} \alpha / \sigma_{1}\right)
$$

where

$$
\text { (II. 7) } M\left(Z \alpha / \sigma_{1}\right)=\frac{\mathrm{f}\left(\mathrm{Z} \alpha / \sigma_{1}\right)}{\mathrm{F}\left(\mathrm{Z} \alpha / \sigma_{1}\right)}
$$

is the inverse of the so called "Mills'-ratio" and $f(\cdot)$ and $F(\cdot)$ denote the distribution function and the cumulative distribution function of $Z \alpha / \sigma_{1}$, respectively. The derivative of $M$ with respect to $Z \alpha / \sigma_{1}$ is positive, hence the greater $\mathrm{Z} \alpha / \sigma_{1}$ the more important is the bias.

A consistent estimate of $\alpha / \sigma_{1}$ can be obtained by applying the probit method using the dummy variable $D$ as a function of the variables $Z$. We then can evaluate $M$ explicitly for each individual using the estimated $Z \hat{Q} / \hat{\theta}_{1}$. Next, we estimate equation (II.6) by ordinary least squares. As has been shown by J.J. Heckman (1976) this procedure will yield consistent (but not fully efficient) estimates of $\beta$. Note, however, that the formula for standard errors for least squares coefficients understate the true standard error and overstate estimated significance levels. $\underline{22 /}$

\section{EMPIRICAL RESULTS}

The estimation procedure is carried out in two steps.

(i) We first check for omitted variable bias. Applying the probit method we estimate the probability of "having the information" and calculate the inverse of the Mills' ratio.

(ii) We then estimate the regressions on the reservation wage according to the considerations of the theoretical section. 
To begin with, Table 1 presents the probit estimates $\frac{23 /}{\text { of }}$ "having the data on incomes" $(D=1)$ or not $(D=0)$. The independent variables need some comments. The variable "work experience" perhaps should capture better information on the wage offer distribution if the individual has worked before. A similar effect is attributed to the variable "position before becoming unemployed"; compared to white-collar workers, a blue-collar worker may not undertake much search efforts. Besides this, blue-collar workers include temporary workers with no clear idea of their reservation wage and those temporary workers who take whatever job they can get. Twice the log likelihood (negatively) gives 176.568 - indicating that the null hypothesis of insignificance of all parameters can be rejected. $24 /$ Since the probit model is based on the cumulative normal probability function, the question may be raised as to whether the results are an artifact of the distribution. As has been shown by D.R. Cox, for example, the numerical difference between a probit and a logit model $\frac{25 /}{}$ is very small over the entire range of both distribution functions with the only exception at their extremes. We want to point out, however, that other possibilities such as angular transformations are not considered in this paper.

In the next step, the Mills' ratio is evaluated for each individual using the parameter estimates of the probit method. This procedure ensures that we will obtain consistent estimates of the parameters if the inverse of it is added as an independent variable to the regression equation on the reservation wage.

As has already been pointed out in the theoretical section, independent variables and their definitions are dictated by the data set. In addition, some efforts have been made to enrich the list of variables by constructing variables such as entitlement to unemployment compensation, for example, and 
Table 1: Probit Estimates of the Probability whether an Information about Incomes is given $(D=1)$ or not $(D=0)$.

\begin{tabular}{|c|c|c|c|}
\hline $\begin{array}{l}\text { Explanatory } \\
\text { Variables }\end{array}$ & $\begin{array}{l}\quad \mathrm{z}_{1}: \\
\text { Work Experience } \\
(1=\text { yes, } 0= \\
\text { otherwise })\end{array}$ & $\begin{array}{l}\quad z_{2} \text { : } \\
\text { Position before } \\
\text { Becoming unem- } \\
\text { ployed ( } 1 \text { = wor- } \\
\text { ker, } 0 \text { = other- } \\
\text { wise) }\end{array}$ & $\begin{array}{l}\mathrm{z}_{3}: \\
\text { Citizenship } \\
(1=\text { German, } \\
0=\text { otherwise })\end{array}$ \\
\hline $\begin{array}{l}\text { Estimated } \\
\text { Parameters } \\
\text { ( } t \text {-values } \\
\text { in brackets) }\end{array}$ & $\begin{array}{l}0.959 \\
(9.5)\end{array}$ & $\begin{array}{l}-0.351 \\
(9.0)\end{array}$ & $\begin{array}{l}0.155 \\
(2.7)\end{array}$ \\
\hline $\begin{array}{l}\text { Log Likeli- } \\
\text { hood Function }\end{array}$ & -3042.885 & $\begin{array}{l}-1.735 \\
(15: 7)\end{array}$ & \\
\hline $\begin{array}{l}\text { Number of } \\
\text { observations }\end{array}$ & 6572 & & \\
\hline
\end{tabular}

Probability that the information on income is given is:

$$
\int_{-Z \alpha / \sigma_{1}}^{\infty} \frac{1}{\sqrt{2 \pi}} e^{-v^{2} / 2} d v
$$


by including variables from other statistics such as demand side variables and wage offer distributions. $\underline{26 /}$ Any variable that was in the data set and was thought to reflect the individual's search strategy is included in the regression. Not all observed variables, however, can be derived directly and explicitly from search theory, but serve merely as proxies for unobserved variables such as discount rates and the degree of risk aversion. The difficulty is due to the identification problems which cloud the issues. For illustration, consider age as one of the explanatory variables. $\stackrel{27 /}{ }$ The theoretical upshot of this variable is ambiguous since it may reflect a shorter remaining working life, a lower discount rate, or a greater variance in the offer distribution (not adequately taken into account by the construction of this distribution). Column 1 of Table 2 lists the coefficients of regression on the $\log$ of the reservation wage and Table 3 presents a list of symbols and definitions of variables. The logarithm of $w^{\mathrm{R}}$ has been chosen since test for normality $28 /$ did reveal that the null hypothesis of non-normality could be rejected at a higher significance level for $1 \mathrm{n} \mathrm{w}^{\mathrm{R}}$. The value of the $\log$ likelihood function and the standard error of the regression are reported at the bottom of each column. " $t$ "-values are in brackets but recall that they understate the true standard error in the case of sample selection bias. Column 2 reports the beta coefficients in order to compare the magnitude of the influence of each variable. $\underline{29 /}$

The higher the mean of the wage offer distribution the individual is facing, the higher the reservation wage. This theoretical argument is confirmed by the estimates, the elasticity of the reservation wage with respect to the mean of the wage offer distribution is 0.27 . The effect of the standard deviation of the wage offer is theoretically ambiguous, depending on whether or not the reservation wage is higher than the mean of the wage offer distribution. Since 
Table 2: Regression Results

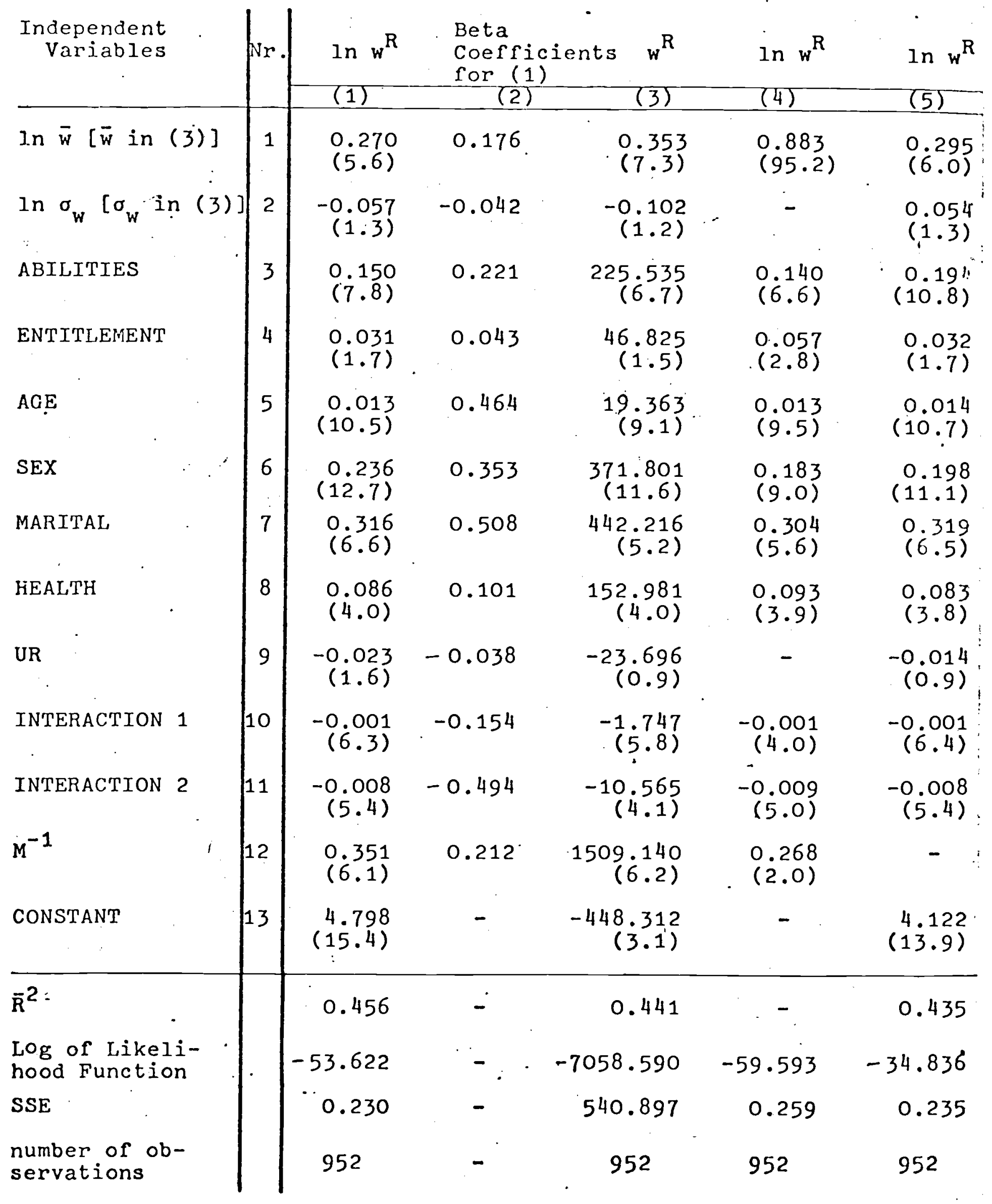


Table 3: List of Symbols
ABILITIES $\quad=1$ if minimum requirements for school educa- tion, vocational training, and work experience according to the occupation are fulfilled, o otherwise

$A G E$

$=$ age

ENTITLEMENT $=1$ if entitłed for unemployment compensation, o otherwise

HEALTH

$=1$ if no restrictions concerning health condition, $o$ if there are restrictions

INTERACTION 1 = bivariate interaction term between $A G E$ and UP

INTERACTION 2 . = bivariate interaction term between $A G E$ and MARITAL

$M$

$=$ Mills'ratio

MARITAL

$=1$ if married, o otherwise

SEX

$=1$ if male, o otherwise

SSE

$=$ standard error of the regression

UR

= aggregate unemployment rate at the beginning of the recent spell of unemployment

UP

$=$ number of previous spells of unemployment $\bar{w}, \quad \sigma_{w}$

$=$ mean and standard deviation of the wage offer distribution the individual is facing (divided by 1000)

= reservation wage 
both means are approximately equal, $\underline{30 /}$ there should be no important effect of $\sigma_{w}$ on $w^{R}$. This is confirmed by the low significance level and the low value of the beta coefficient of the $\sigma_{w}$ variable. Note, however, that no claim is made that the wage offer distribution used in this study gives a realistic picture since only a distinction with respect to profession is made. As a consequence, the influence of many independent variables is partly due to omitted heterogeneity of the wage offer distribution. Moreover, long-term unemployed may not have the choice over the entire distribution but only over the lower left area of the distribution due to missing work experience, for example. Both higher abilities and the entitlement to unemployment compensation unambiguously increase the reservation wage on theoretical grounds. The empirical results support this hypothesis, but the importance of the entitlement is rather low. Therefore, this study gives no basis for an empirical justification of substantially higher reservation wages of insured, unemployed people. Note, however, that only the fact $\frac{31 /}{}$ of whether the individual is or is not entitled could be included and not the amount of the unemployment compensation. Sex seems to be an important variable (with regard to the beta-coefficient) indicating an unequal (reservation) wage structure to the disadvantage of female unemployed persons. $\underline{32 /}$

Although an interaction term between SEX and ABILITIES was insignificant at the $5 \%$ level, the suspicion may be raised that the higher reservation wage of male unemployed persons is due to a higher proportion of better educated and trained men with more work experience than women entering the labor force after a period of non-market activities.

Restricitions with respect to health conditions have a negative impact on the reservation wage too. More surprisingly, demand conditions - represented by the overall unemployment rate - seem to have a rather low influence on the 
amount of the reservation wage. Although there is some variability in the unemployment rate due to different durations of unemployment the significance of the coefficient of this variable is rather low. Perhaps one reason for this result is that regional unemployment rates are a much better indicator of the demand conditions the individual is facing. But the data set does not give any information about the residence of the unemployed person.

The impacts of age and marital status on the reservation wage are related due to the interaction term. The effect of age depends on the marital status and the number of previous spells of unemployment. More precisely, if no previous spells of unemployment occur, the effect of age on the reservation wage is always positive, but lower for married unemployed persons. To state it theoretically, although a higher age results in a lower remaining working life, this negative effect on the reservation wage is offset by the higher reservation wage due to the expectation that the employer will value a longer work experience. In the case the individual is married, however, this age effect is lowered because the search costs are higher. The opportunity costs are greater for a married searcher due to higher net incomes not earned while unemployed which may outweigh higher unemployment compensation for married unemployed. Besides this a married unemployed may be more risk averse than a single one if he is the breadwinner of the family. As has been shown in the theoretical section, risk aversion leads to a lower reservation wage. Consequently, the effect of the marital status on the reservation wage is negative, but only if the individual is older than 38 years. If the individual is younger, a married, unemployed person has a higher reservation wage than a single one. The reason for this may be that the spouse is working and that the higher unemployment compensation for married unemployed outweighs the effect of risk aversion mentioned above. During this age the difference between net incomes is smaller due to lower gross incomes and the progressive 
tax system, but there may be a greater relative difference in gross incomes between young married and non-married persons $33 /$ since the employer often takes into account the number of dependents when offering a wage to a younger married applicant. Since the searcher knows or expects this behaviour he raises his reservation wage. Besides this, the effect of more risk aversion for married persons does not play an important role for young couples if both are working and/or supported by their parents.

One major disadvantage of the data set is that it does not allow us to test the hypothesis of a declining reservation wage while unemployed. The only possibility is to take into account the amount of previous spells of unemployment. We want to stress, however, that this variable is a rather crude proxy only. Although the variable UP significantly enters the regression equation as an interaction term with AGE, a main effect of UP has not been significant at even low standards. Excluding the main effect violates the hierarchical structure of the mode $1 \frac{34 /}{}$ and implies a so-called "synergistic" model. $\frac{35 /}{}$ The interpretation is that if the age variable is low, the number of previous spells of unemployment does not have an important effect on the reservation wage. Virtually no teenager entering working life has previous spells of unemployment. As the regression results and the beta coefficient Indicate the magnitude of the impact of the UP variable (in connection with the AGE variable) is not very impressive. Thus, there is no strong evidence that previous spells of unemployment play more than a lower-order role. Although this result cannot be transferred to the impact of the duration of the current spell of unemployment without several caveats, the suspicion may be raised that the reservation wage will not be influenced very much by the individual unemployment experience. $\underline{36 /}$

More technical isssues of the estimates are discussed next. In order to make sure that the results are not an artifact of the logarithmic specification 
of $w^{R}, \vec{w}$, and $\sigma_{w}$ column (3) of Table 2 presents an estimation using nonlogarithmic values of these variables and where all other variables retain their prior meaning. As can be seen, the signs of the variables do not change and beta coefficients (not reported again) do not indicate a change in the importance of a variable. The significance level of the UR variable, however, is reduced substantially. In order to check for normality of the dependent variables $1 n w^{R}$ and $w^{R}$, a test whether this assumption can be rejected is in order. Such a test can be performed by testing the normality of the error terms. The chosen test is the SHAPIR0-WILK test $\frac{37 /}{4}$ since it is specifically designed for a Gaussian null hypothesis and therefore its power characteristics indicate that it usually will outperform other tests. $\frac{38 /}{}$ The calculated Shapiro-Wilk statistic is 0.9978 and 0.9732 for the logarithmic and the nonlogarithmic version. The critical values above which the hypothesis of nonnormality can be rejected are 0.991 and 0.985 at $1 \%$ and $10 \%$ respectively. Hence, the null hypothesis of non-normality can be rejected for the logarithmic value but not for the non-logarithic value at conventional significance levels. Although the intercept is significant at a rather high level one might be tempted to analyze to what extent it incorporates effects attributed to the other concomitant variables of the equation. As it is well known from the

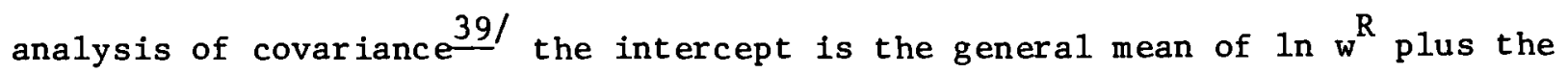
mean of the continuous variables multiplied by their regression coefficients. To put it differently, the intercept can be interpreted as the mean of $1 n w^{R}$ if the continuous concomitant variables are measured as deviations from their means. In non-logarithmic values, the intercept $(\hat{=} 121)$ is 8 p.c. of the geometric mean of $w^{R}(7.350 \hat{=} \ln 1555)$. As column 4 shows, $\frac{40 /}{=}$ the major effect of estimating a homogeneous regression is the increase of the regression coefficient of $\ln \overline{\mathrm{w}}$ and $\mathrm{M}^{-1}$ and the insignificance of $\ln \sigma_{\mathrm{w}}$ and UR. Since job search theory usually provides no basis for whether or not an intercept 
should be included, it is reassuring that this does not substantially affect the magnitude of the coefficients of other economic variables with the exception of that of $\mathrm{ln} \overline{\mathrm{w}}$. Hence, we may conclude that the constant term contributes a major share of the influence of $\ln \overline{\mathrm{w}}$ and $\mathrm{M}^{-1}$ on $\ln \mathrm{w}^{\mathrm{R}}$.

In order to test for a sample selection bias more genera1ly, column (5) presents the regression equation of column (1) without the $M^{-1}$ term. Although there is no substantial change in the value of the parameters, some coefficients are subject to a sample selection bias. This bias results in an overestimation of the influence of abilities, but underestimates the effect of sex. Twice the difference in the $\log -1$ ikelihoods strongly exceeds the critical $\chi^{2}(1)=3.84$. Hence, we can reject the hypothesis of no sample selection bias. The source of this bias can be detected by evaluating the correlation between the residuals of the $\ln w^{R}$ equation and those of the probit specification, $\rho 12^{\circ}$

As has been mentioned in the methodological section, the coefficient of the $M^{-1}$ term equals $\rho_{12} \sigma_{2} \cdot \frac{41 /}{}$ The variance $\sigma_{2}^{2}$ is downward biased, however, but it can consistent1y be estimated by: $\underline{42 /}$

$$
\hat{\sigma}_{2}^{2}=\frac{1}{N} \sum_{i=1}^{N} \hat{u}_{i}^{2}-\hat{b}^{2} \sum_{i=1}^{N} M_{i}^{-1}\left(\hat{z}_{i}-M_{i}^{-1}\right),
$$

where $\hat{b}$ is the regression coefficient of $\mathrm{M}^{-1}$. From this procedure we obtain estimates $\hat{\rho}_{12}=0.788$ and $\hat{\sigma}_{2}=0.455$. Compared with the rather minor change in the parameter values between column (1) and column (5), a correlation coefficient $\hat{\rho}_{12}^{2}=0.621$ between the residuals seems to be a little too high. Note, however, that $\hat{\rho}_{12}$ is subject to a standard error (which has not been derived explicitly yet). In fact, other studies show $43 /$ that this approach may slightly overshoot the adjustment for selectivity bias compared with joint maximum-1ikelihood estimates of $\rho_{12}, \sigma_{2}$, and the regression coefficients. $44 /$ 


\section{CONCLUSION AND POLICY IMPLICATIONS}

This study represents a start on empirical work on the reservation wage of unemployed persons in Germany. The advantage of this analysis is that it allows us to estimate the reservation wage as long as some basic individual characteristics are available.

With respect to policy implications two major issues should be pointed out. First, there is a positive effect of the entitlement to unemployment compensation on the reservation wage and, hence, on the duration of unemployment. But this influence is rather small. Therefore, this study does not provide a basis for proposals to change the unemployment insurance system. Second, higher abilities lead to a higher reservation wage. This result may outweigh the effect that higher abilities raise the probability that the individual receives a job offer. As a consequence, the duration of unemployment may be longer for those individuals with a better education and/or vocational training. A policy which improves the educational level of unemployed is of course recommendable since it reduces the risk to become unemployed but the policy maker should keep in mind that this measure is not necessarily an employment policy in the sense that it reduces the duration of unemployment directly.

Many variables of search models are difficult to observe and the theory itself contains rather sophisticated behavioral relationships. In order to come into contact with empirical phenomena, it has been necessary to withdraw from the burden of high-powered theory. Hence, a further piece of research needed in job search models is to provide a more sound empirical basis than is available to us. For example, panel data on unemployed persons of short subsequent time periods would allow us to more explicitly test the hypothesis of a decreasing reservation wage while unemployed. Questions about the wage offer distribution would give some insights as to whether or not the individual has sufficient information about it. 
Obviously, much more work needs to be done. The goal to be capable of answering some more questions about labor market behaviour is worthy of further efforts. It might then be the appropriate time to decide to what extent job search models describe reality or are fine arts of economic theory. 


\section{FOOTNOTES}

I/ For recent surveys, see H. König (1979), S. Lippman and J. McCall (1976), and K.W. Rothschild (1979), for example.

2/ See S. Nicke11 (1979), p. 1251.

3/ See N. Kiefer and G. Neumann (1979a), p. 91.

4/ Although the following results are standard in job search models we present the derivation at some length since their explanation is sometimes rather cursory. For an exception, see J. Addison and W. Siebert (1979), p. 197.

5/ For a discussion of search costs and the duration of unemployment see W. Mellow (1978) who uses the residuals from a hedonic wage regression as a measure of search costs. For a distinction of how much time and money is devoted to job search, see J.M. Barron and W. Mellow (1979).

6/ For examples, see N. Kiefer and G. Neumann (1979) and S. Nicke11 (1979).

I/ For retirement considerations see R.H. Gordon and A.S. Blinder (1980).

8f See R. Gronau (1971). For the effect of initial wealth endowment, see J.P. Danf orth (1979).

9! See D. Mortensen (1977), W. Franz (1979). In an empirical study for Sweden, A. Björklund (1978) obtains a negative sign of the unemployment insurance variable in a logit approach of survival rates of unemployed.

10/ See M. Rothschild (1974) for a derivation of this result and M.G. Kohn and S. Shavell (1974) for a discussion of the effects of different beliefs about the wage offer distribution.

11/ See K.B. Clark and L.H. Summers (1979) on this point also. For effects of introducing the probability of being recalled by the employer in the case of a temporary lay off, see J.M. Barron and W. Mellow (1979).

12/ We note parenthetically that the difference between maximizing either the expected utility of the present value of income (net of search costs) or the expected utility of lifetime consumption is of some importance. If the direct utility function, for example, is non-linear in consumption, the conditions which allow income to be included as the sole argument in a direct utility function do not necessarily hold. For a discussion of why these conditions are violated see M. Spence and R. Zeckhauser (1972) and J.P. Danforth (1977).

13/ This can be achieved by defining $r_{U} \equiv-U^{\prime \prime}(x) / U^{\prime}(x)$ as a measure of absolute risk aversion when the utility function is $U(x)$. If $r_{U}$ is a falling function of wealth, the searcher's risk aversion increases as wealth declines. See J.R. Hall, S.A. Lippman and J.J. McCall (1979), and D.C. Nachman (1975). 
14/ See also K.P. Classen (1979).

15/ See equation (I.7a). See also N.M. Kiefer and G.R. Neumann (1979a) for a discussion.

16/ For a formal derivation of this result see H. König (1979), M. Rothschild (1974), and M.G. Kohn and S. Shavell (1974), for example.

17/ See S.W. Salant (1977).

$18 /$ We do not report numerous difficulties with the data. Due to a strange coding each individual had to checked for plausibility.

19/ Since the following considerations are standard results we only present the main results. For an extensive treatment see, for example, J.J. Heckman (1976) and Z. Griliches, B.H. Hall, and J.A. Hausman (1978).

20/ This threshold can be assumed to be zero without any loss of generality.

21/ See Z. Griliches, B.H. Hall and J.A. Hausman (1978, p. 144).

22/ See J.J. Heckman (1979), pp. 158-160.

23/ Since probit analysis is standard in modern econometric textbooks, the reader is referred to H. Theil (1971), pp. 630-631, and R.S. Pindyck and D.L. Rubinfeld (1976), pp. 245-247.

24/ Given a 0.0005 p.c. significance limit, the critical value above which the null hypothesis can be rejected is 17.730 for 3 degrees of freedom.

25/ D.R. Cox (1970), pp. 27-28.

26/ A description of the wage offer distribution is contained in an appendix available on request. To summarize shortly, the mean and variance of wages are taken from a $1 \%$ census in 1976. The data basis is monthly net income distinguishing several professions.

27/ See K.P. Classen (1979), p. 201 for this point.

28/ See also p. 22 .

29/ Beta coefficients are defined as the estimated parameter value of each independent variable multiplied by the ratio of the standard error of this variable and the standard error of the dependent variable. For a discussion, see D.J. Aigner (1971), pp. 72-80, for example.

30/ The mean of $\ln w^{R}$ and $\ln \bar{w}$ is 7.349 and 7.403 , respectively.

31/ Which is an estimate itself.

32/ For a study of determinants of the reservation wage of mature women see S.H. Sande11 (1980). 
33/ In the public sector, for instance, there is a difference in incomes between married and not married employees regardless of their age.

34/ The requirement of a hierarchical structure is important in the context of loglinear models. See S.E. Fienberg (1977), p. 39.

35/ For an example see Y.M.M. Bishop, S.E. Fienberg, and P.W. Holland (1975), p. 112 .

36/ Empirical work by H. Saterdag (1975) which is based on interviews, shows that unemployed people were somewhat unwilling to accept a lower income in order to receive a new job, although their willingness increased a little with a longer duration of unemployment.

37/ For a description including tables see S.S. Shapiro and M.B. Wilk (1965). The observations have been grouped into 50 groups.

38/ For a discussion of this point, see E.F. Fama and R. Roll (1971).

39/ See H. Scheffé (1959), pp. 194-195 for a proof. For a basic introduction to variance and covariance analysis, see H.J. Schalk (1975).

40/ $\bar{R}^{2}$ has been dropped since its interpretation becomes difficult in a homogeneous regression. In this case the ratio of the sum of squares of the regression to the total sum of squares can exceed the 0,1-interval. For more details, see D. Aigner (1971), pp. 85-90.

41/ $\sigma_{2}^{2}$ is the variance of the residuals of the $\ln w^{R}$ equation.

42/ See J.J. Heckman (1979), p. 157 (the above formula is corrected for print errors).

43/ See Z. Griliches, B. Ha11 and J.A. Hausman (1978), p. 147.

44/ Which are much more elaborate but do not result in a large gain of efficiency. 


\section{REFERENCES}

Addison, J.T. and W.S. Siebert (1979), The Market for Labor: An Analytica1 Treatment, Santa Monica.

Aigner, D.J. (1971), Basic Econometrics, Englewood Cliffs.

Barnes, W.F. (1975), Job Search Models, The Duration of Unemployment, and The Asking Wage: Some Empirical Evidence, The Journal of Human Resources, 10, pp. 230-240.

Barron, J.M. and O.W. Gilley (1979), The Effect of Unemployment Insurance on the Search Process, Industrial and Labor Relations Review, 32, pp. 363-366.

Barron, J.M. and W. Mellow (1979), Search Effort in the Labor Market, Journal of Human Resources, 9, pp. 389-404.

Bishop, Y.M.M., S.E. Fienberg and P.W. Holland (1975), Discrete Multivariate Analysis: Theory and Practice, Cambridge.

Björklund, A. (1978), On the Duration of Unemployment in Sweden, 1965-1976, Scandinavian Journal of Economics, 80, pp. 421-439.

Burdett, K. (1979), Unemployment Insurance Payments As A Search Subsidy: A Theoretical Analysis, Economic Inquiry, 17, pp. 333-343.

Burdett, K, and D.T. Mortensen (1979), Search, Layoffs, and Labor Market Equilibrium, The Center for Mathematical Studies in Economics and Management Science, Northwestern University, Discussion Paper No. 380, Evanston, I11.

Chapin, G. (1971), Unemployment Insurance, Job Search, and the Demand for Leisure, Western Economic Journal, pp. 102-107.

Clark, K.B. and L.H. Summers (1979), Labor Market Dynamics and Unemployment: A Reconsideration, Brookings Papers on Economic Activity, 1:1979, pp. 13-60.

Classen, K.P. (1979), Unemployment insurance and job search, in: S.A. Lippmann and J.J. McCall (eds.), Studies in the Economics of Search, Amsterdam, pp. 191-219.

Crosslin, R.L. and D.W. Stevens (1977), The Asking Wage - Duration of Unemployment Relation Revisited, Southern Economic Journal 43, pp. 1298-1302.

Cox, D.R. (1970), The Analysis of Binary Data, London.

Danforth, J.P. (1979), On the role of consumption and decreasing absolute risk aversion in the theory of job search, in: S.A. Lippmann and J.J. McCall (eds.), Studies in the Economics of Search, Amsterdam, pp. 109-131. 
Danforth, J.P. (1977), Wealth and the Value of Generalized Lotteries, Journal of Economic Theory, 15, pp. 54-71.

Fama, E.F. and R. Roll (1971), Parameter Estimates for Symmetric Stable Distributions, Journal of the American Statistical Association, 66 , pp. 331-338.

Feinberg, R.M. (1978), On the Empirical Importance of the Job Search Theory, Southern Economic Journal, 16, pp. 508-521.

Feinberg, R.M. (1977), Risk Aversion, Risk, and the Duration of Unemployment, Review of Economics and Statistics, 59, pp. 264-271.

Fienberg, S.E. (1977), The Analysis of Cross-Classified Categorical Data, Cambridge, Mass.

Franz, W. (1979), The Duration of Youth Unemployment in West Germany: Some Theoretical Considerations, National Bureau of Economic Research, Working Paper No. 397, Cambridge, Mass.

Gordon, R.H. and A.S. Blinder (1980), Market Wages, Reservation Wages, and Retirement, National Bureau of Economic Research, Working Paper No. 513 (July, 1980), Cambridge, Mass.

Griliches, Z., B.H. Hall and J.A. Hausman (1978), Missing data and self-selection in large panels, Annales de l'insee, 30-31, pp. 137-176.

Gronau, R. (1971), Information and Frictional Unemployment, American Economic Review, 61, pp. 290-301.

Hall, J.R., S.A. Lippman and J.J. McCall (1979), Expected utility maximizing job search, in: S.A. Lippman and J.J. McCall (eds.), Studies in the Economics of Search, Amsterdam, pp. 133-155.

Hall, R.E. (1978), Stochastic Implications of the Life Cycle-Permanent Income Hypothesis: Theory and Evidence, Journal of Political Economy, 86, pp. $971-987$.

Heckman, J.J. (1979), Sample Selection Bias as a Specification Error, Econometrica, 47, pp. 153-161.

Heckman, J.J. (1976), The Common Structure of Statistical Models of Truncation, Sample Selection, and Limited Dependent Variables and a Simple Estimator for Such Models, Annals of Economics and Social Measurement, 5, pp. 475-492.

Hicks, J.R. (1938), Value and Capital. An Inquiry into some Fundamental Principles of Economic Theory, Oxford.

Kiefer, N.M. and G.R. Neumann (1979a), An Empirical Job-Search Model, with a Test of the Constant Reservation-Wage Hypothesis, Journal of Political Economy, 87, pp. 89-107. 
Kiefer, N.M. and G.R. Neumann (1976), Estimation of wage offer distributions and reservation wages, in: S.A. Lippman and J.J. McCall (eds.), Studies in the Economics of Search, Amsterdam, pp. 171-189.

Kohn, M.G. and S. Shave11 (1974), The Theory of Search, Journal of Economic Theory, 9, pp. 93-123.

König, H. (1979), Job-Search-Theorien, in: G. Bombach, B. Gahlen and A.E. Ott (eds.), Neuere Entwicklungen in der Beschäftigungstheorie und-politik, Tübingen, pp. 63-121.

Lippman, S.A. and J.J. McCa11 (eds.) (1979), Studies in the Economics of Search, Amsterdam.

Lippman, S.A. and J.J. McCal1 (1976), The Economics of Job Search, Economic Inquiry, 14, pp. 155-189 and pp. 347-398.

Maddala, G.S. (1978), Selectivity problems in longitudinal data, Annales de 1'insee, 30-31, pp. 423-450.

Malinvaud, E. (1966), Statistical Methods of Econometrics, Amsterdam.

Mellow, W. (1978), Search Costs and the Duration of Unemployment, Economic Inquiry, 16, pp. 423-430.

Mortensen, D.T. (1977), Unemployment Insurance and Job Search Decisions, Industrial and Labor Relations Review, 30, pp. 505-517.

Nachman, D.C. (1975), Risk Aversion, Impatience, and Optimal Timing Decisions, Journal of Economic Theory, 11, pp. 196-246.

Nicke11, S. (1979), Estimating the Probability of Leaving Unemployment, Econometrica, 47, pp. 1249-1266.

Pindyck, R.S. and D.L. Rubinfeld (1976), Econometric Models and Economic Forecasts, New York.

Rothschild, K.W. (1979), Unvollkommene Information und Arbeitsmarkt, WistWirtschaftwissenschaftliches Studium, 8 (November 1979), pp. 518-523.

Rothschild, M. (1974), Searching for the Lowest Price When the Distribution of Prices is Unknown, Journal of Political Economy, 82, pp. 689-711.

Salant, S.W. (1977), Search Theory and Duration Data: A Theory of Sorts, Quarterly Journal of Economics 91, pp. 39-57.

Sande11, S.H. (1980), Job Search by Unemployed Women: Determinants of the Asking Wage, Industrial and Labor Relations Review 33, pp. 368-378.

Saterdag, H. (1975), Situationsmerkmale von Arbeitslosen Anfang 1975 und Voraussetzungen fur die Aufnahme einer neuen Beschäftigung, Mitteilungen aus der Arbeitsmarkt-und Berufsforschung, 8, pp. 136-148. 
Schalk, H.J. (1975), Varianz- und Kovarianzanalyse, in: Methoden der empirischen Regionalforschung, Part 2, Veröffentlichungen der Akademie für Raumforschung und Landesplanung, Vol. 105, Hannover, pp. 87-119.

Scheffé, H. (1959), The Analysis of Variance, New York.

Shapiro, S.S. and M.B. Wilk (1965), An analysis of variance test for normality (complete samples), Biometrica, 52, pp. 591-611.

Spence, M. and R. Zeckhauser (1972), The Effect of the Timing of Consumption Decisions and the Resolution of Lotteries on the Choice of Lotteries, Econometrica, 40, pp. 401-405.

Theil, H. (1971), Principles of Econometrics, Amsterdam.

Yatchew, A. and 2. Griliches (1979), Specification Error in Probit and Logit Models, Harvard Institute of Economic Research, Harvard University, Discussion Paper Number 717 (July 1979), Cambridge, Mass. 